\title{
Article \\ Nucleus Near-Infrared (nNIR) Irradiation of Single A549 Cells Induces DNA Damage and Activates EGFR Leading to Mitochondrial Fission
}

\author{
Momoh Gbetuwa ${ }^{1}\left(\mathbb{D}\right.$, Long-Sheng Lu ${ }^{1,2,3,4,5,6,7} \mathbb{D}$, Tsung-Jen Wang ${ }^{8,9} \mathbb{D}$, Yin-Ju Chen ${ }^{1,2,3,4,5} \mathbb{D}$, \\ Jeng-Fong Chiou ${ }^{3,5,10}$, Tai-Yuan Su ${ }^{11}$ (D) and Tzu-Sen Yang $2,5,12,13,14, *$
}

check for

updates

Citation: Gbetuwa, M.; Lu, L.-S.;

Wang, T.-J.; Chen, Y.-J.; Chiou, J.-F.; Su, T.-Y.; Yang, T.-S. Nucleus Near-Infrared (nNIR) Irradiation of Single A549 Cells Induces DNA Damage and Activates EGFR Leading to Mitochondrial Fission. Cells 2022, 11, 624. https:// doi.org/10.3390/cells11040624

Academic Editors: Tuhin Subhra Santra and Fan-Gang Tseng

Received: 1 January 2022

Accepted: 8 February 2022

Published: 11 February 2022

Publisher's Note: MDPI stays neutral with regard to jurisdictional claims in published maps and institutional affiliations.

Copyright: (C) 2022 by the authors. Licensee MDPI, Basel, Switzerland. This article is an open access article distributed under the terms and conditions of the Creative Commons Attribution (CC BY) license (https:// creativecommons.org/licenses/by/ $4.0 /)$.
1 Graduate Institute of Biomedical Materials and Tissue Engineering, Taipei Medical University, Taipei 110, Taiwan; d825107004@tmu.edu.tw (M.G.); lslu@tmu.edu.tw (L.-S.L.); yjchen1113@tmu.edu.tw (Y.-J.C.)

2 International PhD Program in Biomedical Engineering, Taipei Medical University, Taipei 110, Taiwan

3 Department of Radiation Oncology, Taipei Medical University Hospital, Taipei Medical University, Taipei 110, Taiwan; solomanc@tmu.edu.tw

4 Department of Medical Research, Taipei Medical University Hospital, Taipei 110, Taiwan

5 TMU Research Center of Cancer Translational Medicine, Taipei Medical University, Taipei 110, Taiwan

6 Center for Cell Therapy, Taipei Medical University Hospital, Taipei Medical University, Taipei 110, Taiwan

7 International PhD Program for Cell Therapy and Regeneration, Taipei Medical University, Taipei 110, Taiwan

8 Department of Ophthalmology, Taipei Medical University Hospital, Taipei 110, Taiwan; tjw@tmu.edu.tw

9 Department of Ophthalmology, School of Medicine, College of Medicine, Taipei Medical University, Taipei 110, Taiwan

10 Department of Radiology, School of Medicine, Taipei Medical University, Taipei 110, Taiwan

11 Department of Electrical Engineering, Yuan-Ze University, Chung-Li 32003, Taiwan; tysu@saturn.yzu.edu.tw

12 Graduate Institute of Biomedical Optomechatronics, Taipei Medical University, Taipei 110, Taiwan

13 School of Dental Technology, Taipei Medical University, Taipei 110, Taiwan

14 Research Center of Biomedical Device, Taipei Medical University, Taipei 110, Taiwan

* Correspondence: tsyang@tmu.edu.tw; Tel.: +886-2-27361661 (ext. 5206)

\begin{abstract}
There has been great interest in identifying the biological substrate for light-cell interaction and their relations to cancer treatment. In this study, a near-infrared (NIR) laser is focused into the nucleus (nNIR) or cytoplasm (cNIR) of a single living cell by a high numerical aperture condenser to dissect the novel role of cell nucleus in mediating NIR effects on mitochondrial dynamics of A549 non-small cell lung cancer cells. Our analysis showed that nNIR, but not cNIR, triggered mitochondrial fission in $10 \mathrm{~min}$. In contrast, the fission/fusion balance of mitochondria directly exposed to cNIR does not change. While the same phenomenon is also triggered by single molecular interactions between epidermal growth factor (EGF) and its receptor EGFR, pharmacological studies with cetuximab, PD153035, and caffeine suggest EGF signaling crosstalk to DNA damaging response to mediate rapid mitochondrial fission as a result of nNIR irradiation. These results suggest that nuclear DNA integrity is a novel biological target for cellular response to NIR.
\end{abstract}

Keywords: near infrared (NIR); epidermal growth factor receptor (EGFR); mitochondrial fragmentation count (MFC); mitochondrial dynamic; cetuximab; caffeine; PD153035

\section{Introduction}

Current cancer therapy is composed of three major treatment modalities, including surgery, radiation, and chemotherapy [1]. There is a great interest to improve these modalities or to introduce new modalities to increase therapeutic index and to maximize potential benefits and to minimize the associated risk [2]. Phototherapy is one of such promising modality due to its excellent safety profile and successful preclinical and clinical experiences [2,3]. Near infrared (NIR) light is a reasonable light source for clinical phototherapy 
due to its compatibility with biological tissues, accuracy/sensitivity, and deep penetration into the tissue $(>1 \mathrm{~cm})[2,3]$. Phototherapy is one such promising modality due to its excellent safety profile and successful early clinical experiences. While common cancer therapeutics target subcellular compartments such as the nucleus [4-6], mitochondria [5,7] and the plasma membrane [8-10] to provide anticancer efficiency, the subcellular target for phototherapy remains poorly characterized. NIR light is a reasonable light source for clinical phototherapy due to its compatibility with biological tissues [11,12]. A deeper understanding of the biological basis of subcellular response to NIR will be beneficial to inspire the design of next generation NIR phototherapy. In order to improve the NIR phototherapy and avoid over-dosing related complications, it is very important to understand the biological basis of cellular response to NIR [13]. NIR treatment of cells have a linear relationship (that is, the higher the laser doses, the higher the percentage of cell death). However, this linear relationship has its drawbacks, such as the absence of providing an appropriate or maximum energy dose can affect the therapeutic applications and the higher the laser dose, the higher the harmful effects on the target cells. Nevertheless, studies have shown that the highest percentage of cell death can be achieved at $299,559 \mathrm{~J} / \mathrm{cm}^{2}$ laser dose [14]. In this study, we therefore treated cells with $224.02 \mathrm{~J} / \mathrm{cm}^{2} \mathrm{NIR}$ to achieve a better clinical outcome and to limit the drawbacks of longer exposure to NIR laser light.

Mitochondria are an attractive subcellular target to mediate cell response to NIR. The organelle is the major depot of extranuclear DNA and is responsible for adenosine triphosphate (ATP) synthesis via the electron transport chain. The complex IV in the electron transport chain, responsible for transferring electrons to molecular oxygen and creating electromotive force across the mitochondrial inner membrane, contains cytochrome $\mathrm{c}$ that absorbs NIR, and leads to loss of mitochondrial membrane potential [15]. In addition to energy generation, mitochondria are an organelle hub that integrate environmental signaling inputs. These signals frequently come from growth factor engagement of corresponding receptors on the cell surface, such as epithelial growth factor (EGF) binding to its receptor (EGFR) or activated kinase cascade after deoxyribonucleic acid (DNA) damage as an intrinsic DNA damage response (DDR) $[16,17]$. Furthermore, mitochondria dynamically alter their structure between fusion and fission states in response to these stimuli and crosstalk to the nuclear transcription machinery to orchestrate key cellular fate decisions, including live, death, and stress adaptation [18-20]. Although it has been long known that NIR interferes with mitochondrial signal transduction [21], it remains uncertain about the mechanistic roles by NIR absorption by mitochondrial cytochromes and/or extra-mitochondrial cellular signals.

Epidermal growth factor receptor (EGFR) has been one of the most effective oncogenes that are usually altered in cancers [22]. Inhibitors targeting this pathway significantly improve the clinical outcome in patients with solid tumors that are associated with EGFR mutations [23,24] or gene amplification/overexpression of EGFR proteins [25]. There are seven EGFR ligands that has been described that have shown to induce specific cellular response and intracellular trafficking events that occur in both in vitro and in vivo [26]. These different signaling properties of the various ligands have been related to their ability to differentially stabilize the EGFR dimers which determines the specific signaling output [27]. Targeting overexpressed EGFR proteins with cetuximab enhances mitochondrial-triggered apoptosis and is an effective treatment for EGFR overexpressing tumors [28]. Inhibiting EGFR tyrosine kinase activities with tyrosine kinase inhibitor (such as PD153035) is another approach to control excessive EGFR signaling [29]. Despite its proven importance in clinical oncology, it remains unknown if EGFR signaling is involved in photobiology of cancer cells and therefore be a potential photosensitizing pathway for novel therapeutic development.

Nanodiamonds (NDs) have special carbon nanoparticles that have gained attention for their biocompatibility, high functional surfaces, and their optical and physical properties. These properties have provided a good regenerative platform for medicine that provides an application that ranges from targeted delivery of drugs [30]. They are said to be chemically inert and have a very small cytotoxicity in vivo [31-33]. In drug delivery, one major concern is the toxicity of nanomaterials therefore the material with non-toxic and that is 
biocompatible is highly recommended in clinical use. Other studies have used fluorescence nanodiamond (FND) and cetuximab to target EGFR that expresses cancer cell to deliver drugs [34,35]. We used FND in this study for the targeting of drug delivery approaches and use FND surfaces attached with different ligands such as EGF for the reorganization of EGFR receptor to enhance endocytosis of EGF into the cytosol domain of a cell to facilitate drug such as cetuximab, caffeine, and PD153035 reactivity.

In this study, we examined the effect of NIR on EGFR activities in the presence of treated cells with drugs such as PD153035, caffeine, and cetuximab. NIR treatment in subcellular organelles is very crucial to accurately focus light on the targeted subcellular target of interest. In order to investigate the subcellular substrate for NIR-mitochondrial interaction, our group took a single cell photomodulation approach to explore the role of organelle-directed NIR irradiation. With a single cell photomodulation platform composed of an $830 \mathrm{~nm}$ infrared diode laser, an electrical shutter, laser-focusing optics (condenser), we specifically delivered sublethal levels of NIR laser to either cytosolic mitochondria (cNIR) or nuclei (nNIR) of an A549 cell, which is derived from non-small cell lung cancer with wild type EGFR that only activates the signal upon stoichiometrically matched EGF engagement. First, we quantitatively monitored mitochondrial dynamic change towards fission state as a function of time, which serves as an immediate mitochondrial response to organelle-directed NIR. Then we took advantage of the pharmacological blockade to dissect the relative contribution of EGFR signaling and DDR to immediate mitochondrial response to cNIR and nNIR. Finally, we applied the mitochondrial fragmentation count (MFC) to quantify the mitochondrial pattern and mitochondrial dynamics. Our results show that NIR modulation of mitochondrial dynamics is mainly regulated by cellular signalings, such as EGFR and DDR, rather than by events triggered within the mitochondria.

\section{Materials and Methods}

\subsection{Reagents and Materials}

A549 (adenocarcinoma cells) cell line, Dulbecco's Modified Eagle's Medium—high glucose (DMEM) power, Trypsin and $10 \times$ Phosphate buffer saline (PBS) Sterile, Carbonyl cyanide m-chlorophenyl hydrazone (CCCP) and Mitochondrial division inhibitor 1 (mdivi-1) were ordered from Merck Life Science, Science, Dorset, UK Limited. Cetuximab was bought from Medical Store (MS) Asanwa Ahmedabab Gujarat, India. Caffeine was ordered from CSPC Pharmaceutical Group Limited, Shijiazhuang, China. MitoTracker Green was bought from Thermo Fisher Scientific, Loughborough, UK. Fluorescence Nanodiamond (FND) was bought from FND BIOTECH, Inc. Taipei, Taiwan. PD153035 was bought from MedChemExpress LLC (MCE), Princeton, NJ, USA. Biotin EGF was bought from Molecular Probes, Invitrogen, Carlsbad, CA, USA. Both MitoTracker Green and mdivi-1 were dissolved as stock solutions in dimethyl sulfoxide (DMSO) for dilution in complete media.

\subsection{Cell Culture and Drug Treatments}

A549 cells were cultured in Dulbecco's modified Eagle's medium (DMEM) supplemented with $10 \%$ fetal bovine serum at $37^{\circ} \mathrm{C}$ in a humidified incubator with $95 \%$ air and $5 \% \mathrm{CO}_{2}$ to allow for appreciable confluence. To promote adhesion, cultured cells were seeded on a collagen one-coated glass coverslip microchannel for $22 \mathrm{~h}$ at $37^{\circ} \mathrm{C}$ to ensure $60-70 \%$ cell confluence was achieved. Cultured cells on glass coverslip were then assembled onto the bottom of the flow chamber and treated with $0.3 \mu \mathrm{M}$ MitoTracker Green and incubated for $30 \mathrm{~min}$ at room temperature then washed with PBS.

\subsection{Near Infrared (NIR) Laser Alignment and Florescence Imaging}

The experimental setup for the single-cell NIR laser irradiation system is shown in Figure 1. An $830 \mathrm{~nm}$ (Lambda Beam Wavelock, RGB Photonics, Bavaria, Germany) laser beam was passed through a plano-convex lens L1 (focal length $=25 \mathrm{~mm}$ ) and L2 (focal length $=100 \mathrm{~mm}$ ). The measured output beam diameter was four times that of the input beam. This $830 \mathrm{~nm}$ laser beam then passed through a plano-convex lens L3 (focal length $=125 \mathrm{~mm}$ ) 
and L4 (focal length $=250 \mathrm{~mm}$ ) this makes the total output beam diameter twice that of the input beam thus this laser beam will expand eight times. The laser beam was then reflected by the dichroic mirror D1 (780dcspxr, Chroma Irvine, CA, USA) on the inverted microscope (TE2000U, Nikon, Tokyo, Japan) and passes through the condenser for focus in the sample contained microchannel below, where the laser spot area was $52.36 \mu^{2}$. The back aperture of the condenser was conjugated with mirror M4 and L1 to be able to adjust the position of laser beam in microchannel. Images were obtained by the inverted microscope equipped with an objective lens (Plan Apo 60x/1.40 oil, Nikon, Tokyo, Japan), band-pass filters for a sCMOS camera (ORCA-Flash4.0 V3, Hamamatsu, Japan) and the fluorescence images from cells were acquired with a spatial resolution of image size, $572 \times 332$ pixels (the smallest unit of a digital image) with temporal resolutions of $500 \mathrm{~ms}$ and fluorescence green excitation wavelength $485 \mathrm{~nm}$ an emission of $530 \mathrm{~nm}$ to stain and analyze the mitochondrial structure.

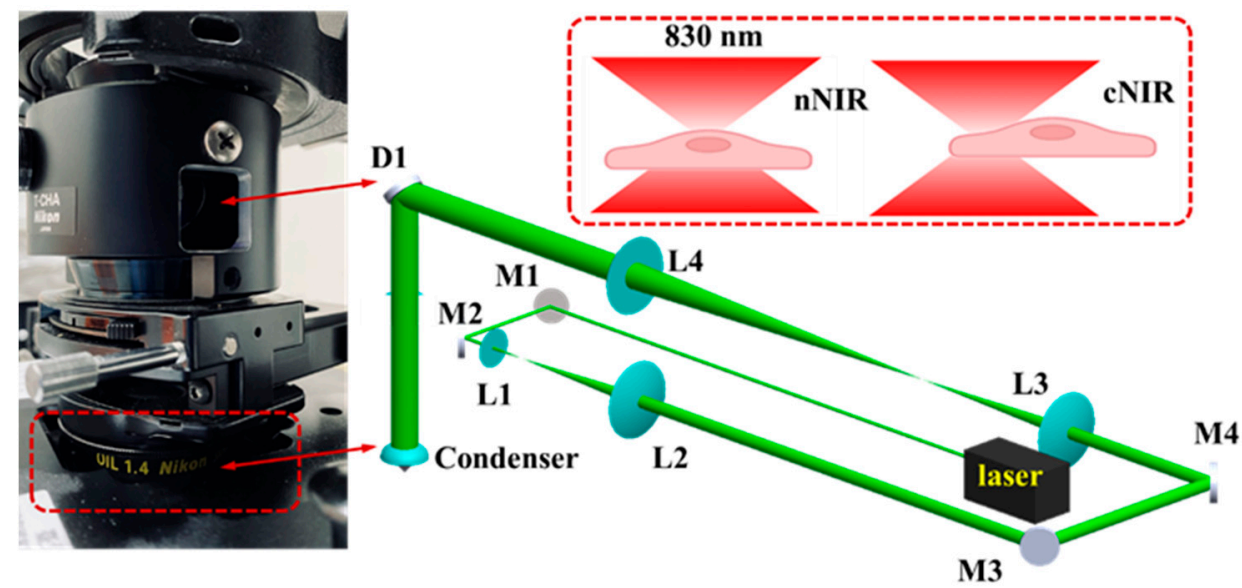

Figure 1. The experimental setup for the single-cell NIR laser irradiation system consists of an $830 \mathrm{~nm}$ infrared diode laser, an electrical shutter, laser-focusing optics (condenser), and a specimen holder attaching to the $\mathrm{XY}$-axis motorized stage. The laser beam is expanded eightfold with lens pairs from the combination of 1:4 telescope (L1:L2) and 1:2 telescope (L3:L4) to slightly fill the back aperture of the condenser, where the dichroic mirror D1 is placed above the condenser to reflect the laser beam into the condenser while transmitting visible light for bright-field imaging. The upper right is the two operation modes for the single-cell NIR laser irradiation: the laser focal spot is located either in the nucleus (nNIR) or in the cytosol (cNIR) of single cell.

\subsection{Single Cell NIR Laser Light Treatment on A549 Cell}

Cultured cells from protocol in Section 2.2. Two cells in the same image plane where one cell was exposed to nucleus $224.02 \mathrm{~J} / \mathrm{cm}^{2} \mathrm{NIR}$ (nNIR), for $10 \mathrm{~s}$ and the other cell not exposed to NIR the cells were then imaged at different time points. Single cell nucleus and cytosol were also exposed to $224.02 \mathrm{~J} / \mathrm{cm}^{2} \mathrm{NIR}$ for $10 \mathrm{~s}$ then imaged cells at $0 \mathrm{~min}$ (Before NIR), 1, 5, 10, 15, and $20 \mathrm{~min}$ and used ImageJ Software to analyze the mitochondrial fragmentation count (MFC), the laser spot is indicated as a small brown circle located either in the nucleus (nNIR) of single cell or in the cytosol (cNIR). In this study, each single cell is being copied five times. That is, for every single cell image there are five images. Therefore, in this study, for a single cell, there were 5 images; for 50 cells there were 250 images; and for 110 cells there were 550 images. The mean and standard error of the mean was therefore determined based on the number of images per cell.

2.5. Carbonyl Cyanide M-Chlorophenyl Hydrazone (CCCP) and Mitochondrial Division Inhibitor 1 (Mdivi-1) Treatment of A549 Cells and Single Cell Exposed to Nuclear NIR (nNIR) in the Same Image Plane

Here, we followed the method in Section 2.2 protocol. Prepare $20 \mu \mathrm{M}$ CCCP reconstituted in DMEM without sodium pyruvate (-sp) and dispense into the volumetric flow system and incubate cells for $30 \mathrm{~min}$ at $37^{\circ} \mathrm{C}$, then washed with $20 \mu \mathrm{M} \mathrm{CCCP}$ reconstituted 
in PBS. We then treated cell with $20 \mu \mathrm{M}$ mdivi-1 reconstituted in PBS and incubate for $30 \mathrm{~min}$ at $37^{\circ} \mathrm{C}$, then wash cells with $20 \mu \mathrm{M}$ mdivi- 1 reconstituted in PBS and imaged 110 single cell each. For the nuclear exposed NIR (nNIR) and the cytosol exposed NIR (cNIR) cells were exposed to nNIR and cNIR for $10 \mathrm{~s}$ the shutter was then closed, and the cells were imaged from $1,5,10,15$, and $20 \mathrm{~min}$.

\subsection{Treatment of A549 Cells with $1 \mu M$ PD153035, FND, 100 nM Cetuximab, 1 mM Caffeine and Conjugated 100 nM FND-EGF}

Culture cells were prepared as in the protocol outlined in Section 2.2. We prepared conjugated $100 \mathrm{nM}$ FND and incubated the cell for $22 \mathrm{~h}$ at $37^{\circ} \mathrm{C}$, the following day we treated the cells again with $1 \mu \mathrm{M}$ PD153035 and conjugated $100 \mathrm{nM}$ FND-EGF, $100 \mathrm{nM}$ cetuximab and conjugated $100 \mathrm{nM}$ FND-EGF and $1 \mathrm{mM}$ caffeine conjugated $100 \mathrm{nM}$ FNDEGF individually, incubated cells for $1 \mathrm{~h}$ at $37^{\circ} \mathrm{C}$ through an inlet port of the flow chamber using an automated syringe pump, incubated cells in a dark with $0.3 \mu \mathrm{M}$ MitoTracker Green reconstituted in PBS at $37^{\circ} \mathrm{C}$ for $30 \mathrm{~min}$. Washed cells with $0.3 \mu \mathrm{M}$ MitoTracker Green, $1 \mu \mathrm{M}$ PD153035 and conjugated 100 nM FND-EGF, $100 \mathrm{nM}$ cetuximab and conjugated $100 \mathrm{nM}$ FND-EGF and $1 \mathrm{mM}$ caffeine conjugated $100 \mathrm{nM}$ FND-EGF all been reconstituted in PBS individually and imaged individually drug treated cell (Before NIR). Expose the nucleus to $224.02 \mathrm{~J} / \mathrm{cm}^{2}$ NIR for $10 \mathrm{~s}$ close laser and image (50 cells) cells at different time points of 10, 20,30,40, and $50 \mathrm{~min}$ for the individual drug treated cells. ImageJ Software was used to analyze the MFC. Due to the different experimental conditions in Section 2.5, different time points were used in this study, such as: (1) mdivi-1 and CCCP, incubated for $30 \mathrm{~min}$ because the drug depreciates over the $30 \mathrm{~min}$ incubation period; (2) MitoTracker Green, incubated for $30 \mathrm{~min}$ because prolonged incubation of MitoTracker Green leads to depreciation of the fluorescent dye; (3) A549 cells were exposed to $224.02 \mathrm{~J} / \mathrm{cm}^{2}$ of NIR for $10 \mathrm{~s}$, as exposure of cells to NIR laser for too long may result in severe tissue damage that will have little or no clinical benefit; and (4) cells were treated with $100 \mathrm{nM}$ FND and incubated for $22 \mathrm{~h}$. The next day, cells were treated with $1 \mu \mathrm{M}$ PD153035 and conjugated with $100 \mathrm{nM}$ FND-EGF and incubated for $1 \mathrm{~h}$, as we realized in this study when cells were treated with $1 \mu \mathrm{M}$ PD153035, conjugated with $100 \mathrm{nM}$ FND-EGF and incubated for $1 \mathrm{~h}$. The next day, cells were treated with $1 \mu \mathrm{M}$ PD153035, conjugated with 100 nM FND-EGF and incubated for $1 \mathrm{~h}$. We therefore designed another experimental protocol by first treating the cells with $100 \mathrm{nM}$ FND and incubating these cells for $22 \mathrm{~h}$. Then the cells were treated again with $1 \mu \mathrm{M}$ PD153035 and conjugated with $100 \mathrm{nM}$ FND-EGF and incubated for $1 \mathrm{~h}$. We observed an increase in the number of FND on the cell membrane, which is shown in Figure S2. The same experimental protocol was applied to cetuximab and caffeine.

\subsection{Mitochondrial Fragmentation Count (MFC)}

MFC is the counting of mitochondrial particle and dividing it by the pixels of mitochondrial network. Using imageJ software, a summary of the average mitochondrial particle count was carried out, and mitochondrial fragmentation count was carried out by calculating the average particle count multiplied by 10,000 on the bases of random choice and then divided by the total mitochondrial pixel $[36,37]$. In this protocol of calculating the MFC, a single numerical value to each cell was assigned.

\subsection{Statistical Analysis}

Statistical comparisons were performed by one-way ANOVA followed by the Newman Keuls post-hoc test (GraphPad Prism software); a value of $p<0.05$ was considered to indicate a statistically significant difference. All data were presented as the mean \pm standard error of the mean (sem). 


\section{Results}

3.1. Single Cell Exposed to Nuclear NIR (nNIR) in the Same Image Plane and Treatment of A549 Cells with Mdivi-1 and CCCP

To demonstrate that the single-cell NIR laser irradiation system can precisely control nNIR at the single-cell level without affecting the nearby cell, a single cell nucleus was exposed to NIR in the same image plane with another cell that was not treated with NIR this is shown in Figure 2A. These cells were imaged from 1, 5, 10, 15, and $20 \mathrm{~min}$, and five mitochondrial fluorescence images were acquired at each observation time point for each single living cell. Therefore, the mean \pm sem of MFC as a function of time can be determined.

A

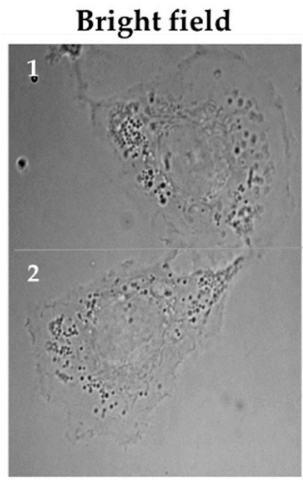

Before NIR

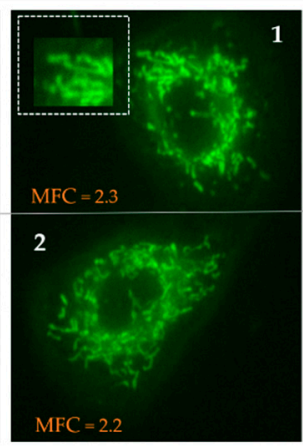

After nNIR

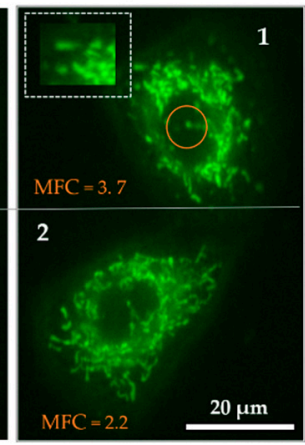

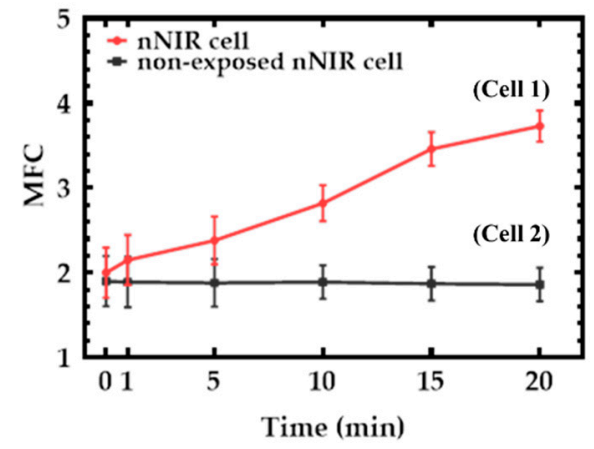

Figure 2. Exposure of A549 cell before and after to nuclear $224.02 \mathrm{~J} / \mathrm{cm}^{2} \mathrm{NIR}$ for $10 \mathrm{~s}$. (A) Cell 1 on the left panel illustrates the bright field of the cell. Cell 1 located in the middle panel is the fluorescence image before nNIR, and cell 1 on the top right panel illustrates cell 1 after 20 min of nNIR (laser spot area in brown circle cell 1), where the fluorescence imaged cell showed a fragmented mitochondrial structure in cell 1 located at the top right panel after $20 \mathrm{~min}$ of nNIR. (B) MFC of single cell nuclear NIR showed a significant $(p<0.01)$ increase of nuclear exposed cell (Cell 1: MFC $=3.7 \pm 0.2)$ but no MFC change in non-exposed nNIR cell (Cell 2: MFC $=1.9 \pm 0.2)$.

Analysis of data showed a significant difference between the mitochondrial patterns (mitochondrial fission) before and after nNIR treatment, as it can be seen in the cropped area of Figure 2A1. At the same time point, the other cell not exposed to NIR showed the similar fine interwoven elongated mitochondrial structure, as shown in Figure 2A2. In addition, there was a significant $(p<0.01)$ increase in MFC (Cell-A1: MFC = $3.7 \pm 0.2)$ for nuclear exposed cell but no MFC change (Cell-A2: MFC $=1.9 \pm 0.2$ ) in non-exposed NIR cell, as shown in Figure 2B.

MFC of cells $(n=110)$ treated with mdivi- 1 showed an elongated well defined mitochondrial structure but CCCP treated cells showed a fragmented and granular mitochondrial structure this is shown in Figure 3A. Analyzed MFC's of cells treated with mdivi-1 and CCCP were compared, cells treated with $20 \mu \mathrm{M}$ mdivi-1 was shown to have a significant $(p<0.01)$ decrease in MFC $(1.5 \pm 0.2)$ but analysis of cells treated with $20 \mu \mathrm{M}$ CCCP showed a very significant $\left({ }^{* * *} p<0.01\right)$ increase in MFC $(4.3 \pm 0.2)$ when compared to the control as shown in Figure 3B.

\subsection{A549 Cell Nuclear and Cytosolic Exposure to $224.02 \mathrm{~J} / \mathrm{cm}^{2} \mathrm{NIR}$}

Figure $4 \mathrm{~A}$ illustrates the differences between mitochondrial dynamics of single A549 cells before $224.02 \mathrm{~J} / \mathrm{cm}^{2} \mathrm{nNIR}$ and after $\mathrm{nNIR}$ for $20 \mathrm{~min}$. The cropped area before and after nNIR illustrating a significant difference between the mitochondrial patterns (mitochondrial fission) and the MFC before and after nNIR treatment. Figure 4B illustrates the differences between mitochondrial dynamics of single A549 cell before $224.02 \mathrm{~J} / \mathrm{cm}^{2} \mathrm{cNIR}$ and after cNIR for $20 \mathrm{~min}$. The cropped area before and after cNIR illustrating no significant change in both the mitochondrial patterns and the MFC before and after CNIR treatment. There was a very significant $\left({ }^{* * *} p<0.01\right)$ gradual increase of MFC after 5 min in single cell nNIR but no change in the MFC in single cell cNIR as shown in Figure 4C. We again exposed 110 
single cells to $224.02 \mathrm{~J} / \mathrm{cm}^{2} \mathrm{nNIR}$ and cNIR, and results showed a significant increase in the MFC of nNIR exposed cells, there was a sharp increase in MFC after 5 min to 15 min, MFC was then stable after 15 min but no significant change in the MFC of cNIR exposed cells Figure 4D. This finding demonstrates that single-cell measurements can identify the individual cellular responses of NIR irradiation and extend to calculate ensemble average when the number of single-cell samples increases.

A

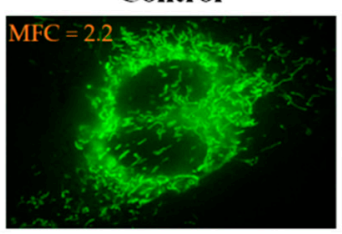

$\mathbf{B}$
$20 \mu \mathrm{M}$ mdivi-1

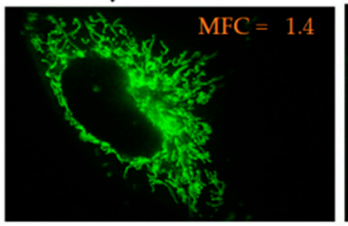

$* * *$

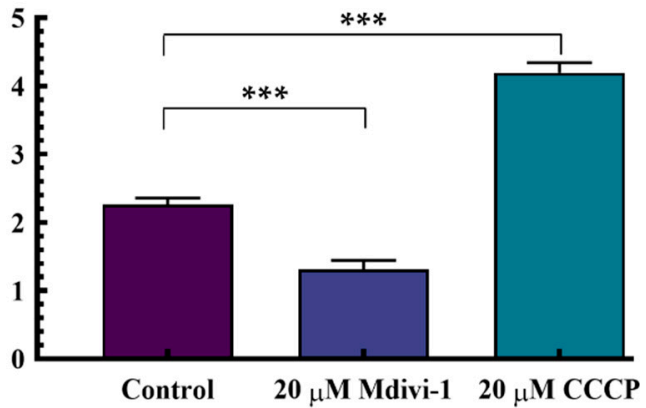

Figure 3. Cells treated with $20 \mu \mathrm{M}$ mdivi-1 and $20 \mu \mathrm{M}$ CCCP. (A) illustrates cells treated with $20 \mu \mathrm{M}$ mdivi-1 and $20 \mu \mathrm{M}$ CCCP and incubated for $30 \mathrm{~min}$. There was a well elongated and distinct mitochondrial structure shown by cells treated with mdivi-1 but a fragmented and granular mitochondrial structure shown for CCCP treated cells compared to the control. There was a significant $(* * *<0.01)$ decrease in MFC $(1.5 \pm 0.2)$ of mdivi- 1 treated cells compared control, but CCCP treated cells showed a very significant $\left.{ }^{* * *} p<0.01\right)$ increase in MFC $(4.3 \pm 0.2)$ compared to the control shown in $(\mathbf{B})$.

\subsection{A549 Cells Treated with FNDs, Free EGF, and 100 nM Conjugated FND-EGF}

In this study, the fluorescent nanodiamond (FNDs) were used as a photostable fluorescent probe for the uptake of FND-EGF by A549 cells. When A549 cells were treated with $100 \mathrm{nM}$ FND, there was indeed a small amount of non-specific uptake of FND in the cytosol of the cell (Supplementary Figure S1). When A549 cells treated with FND for $22 \mathrm{~h}$ and further treated with $100 \mathrm{nM}$ conjugated FND-EGF and incubated for $1 \mathrm{~h}$, the fluorescence images showed very large amount of uptake of FND-EGF in the cytosolic domain of A549 cells (Supplementary Figure S2). This observation supports the statement that FND is only effective when coated with EGF leading to FND-EGF uptake to A549 cells.

In Figure 5, the MFC analysis of cells $(n=50)$ treated with FNDs showed no change in the MFC from $2.1 \pm 0.1$ (time point $0 \mathrm{~min}$ ) to $2.0 \pm 0.1$ (time point $50 \mathrm{~min})(p=0.8)$. The MFC of cells $(n=50)$ treated with free EGF showed an increase in MFC from $2.0 \pm 0.1$ (time point $0 \mathrm{~min}$ ) to $2.7 \pm 0.1$ (time point $50 \mathrm{~min})\left({ }^{* *} p<0.01\right)$. The MFC of cells $(n=50)$ treated with $100 \mathrm{nM}$ FND for $22 \mathrm{~h}$ then later treated with conjugated $100 \mathrm{nM}$ FND-EGF showed a higher increase in MFC from $2.1 \pm 0.1$ (time point $0 \mathrm{~min}$ ) to $2.8 \pm 0.2$ (time point $\left.50 \mathrm{~min}){ }^{* * *} p<0.01\right)$. This finding shows that both free EGF and FND-EGF will lead to mitochondrial fragmentation; namely, the presence of EGF will alter mitochondrial fission. In addition, an increase in FND concentration inside the cytosol domain may induce cell stress and the corresponding mitochondrial dynamics and therefore lead to the highest increase in mitochondrial fragmentation, as shown in Figure 5. 


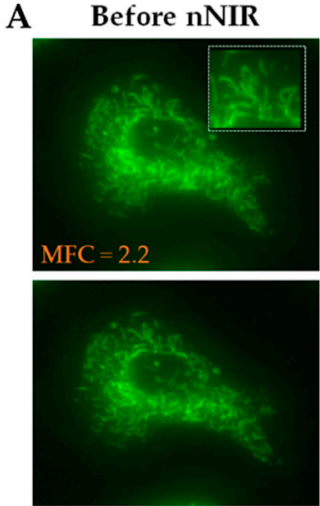

$10 \mathrm{~min}$
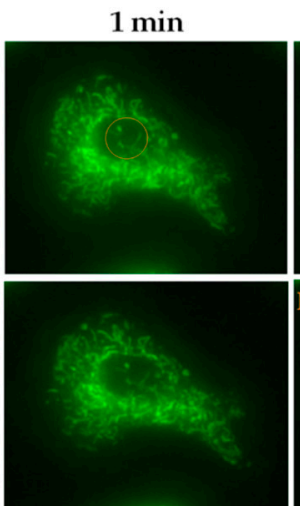

$15 \mathrm{~min}$

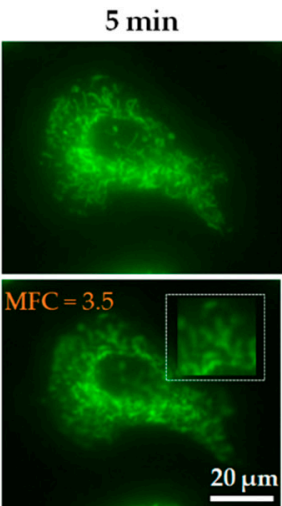

$20 \mathrm{~min}$
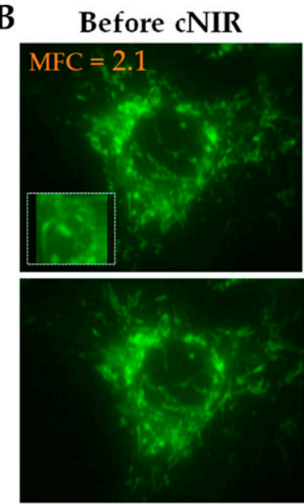

$10 \mathrm{~min}$
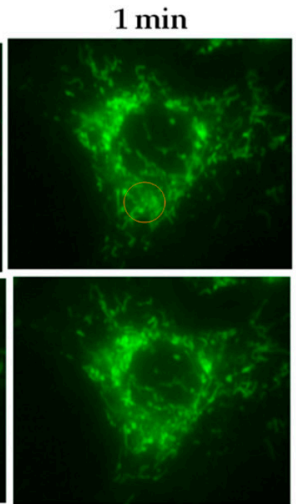

$15 \mathrm{~min}$

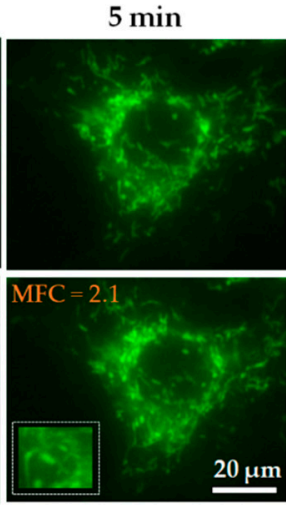

$20 \mathrm{~min}$
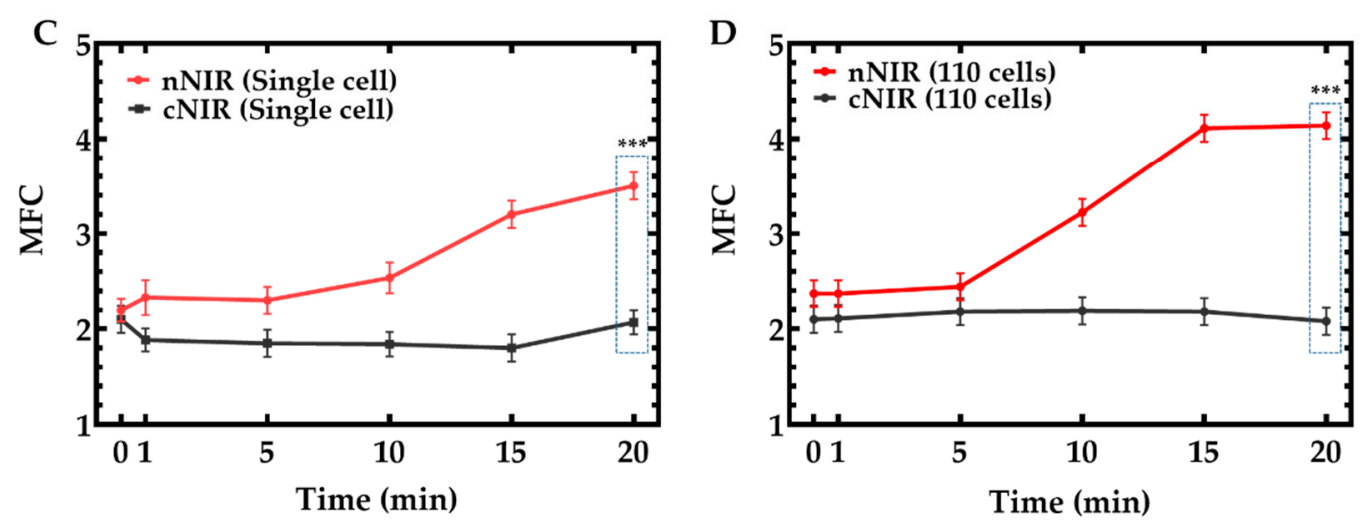

Figure 4. A549 cells $(n=50)$ exposed to $224.02 \mathrm{~J} / \mathrm{cm}^{2} \mathrm{nNIR}$ and $\mathrm{CNIR}$ for $10 \mathrm{~s}$ and imaged in a timedependent manner at $0,1,5,10,15$, and $20 \mathrm{~min}$. (A) Mitochondrial dynamics of a single cell exposed to $224.02 \mathrm{~J} / \mathrm{cm}^{2} \mathrm{nNIR}$ showed significant mitochondrial structural fragmentation. (B) Mitochondrial dynamics of a single cell cytosol exposure to $224.02 \mathrm{~J} / \mathrm{cm}^{2} \mathrm{cNIR}$, and an image analysis showed no significant impact on mitochondrial dynamics. (C) The MFC of a single A549 cell exposed to (A) nNIR and (B) cNIR showed a very significant $(* * *<0.01)$ increase in MFC of nNIR compared to cNIR (MFC: $3.50 \pm 0.2 \mathrm{nNIR} ;{ }^{* *} p<0.01$ vs. $2.1 \pm 0.2 \mathrm{cNIR}$ ). (D) An average of 110 single cells exposed to nNIR and cNIR (MFC: $4.1 \pm 0.3 \mathrm{nNIR}$, vs. $2.1 \pm 0.3 \mathrm{cNIR}$ ) were compared, and there was a very significant $\left.{ }^{* * *} p<0.01\right)$ difference in MFCs after 5 min of NIR exposure between the nNIRand cNIR-exposed cells. Statistical analysis was performed by a one-way ANOVA.

\subsection{A549 Cells Treated with 1 MM PD153035, 100 nM Cetuximab and 1 mM Caffeine in the Presence of $100 \mathrm{nM}$ Conjugated FND-EGF and Then Exposed to $n N I R$}

FND alone treated with A549 cells did not affect MFC as demonstrated in this study from Figure 5. We further use FND alone to investigate the mitochondrial pattern in the absence of EGF stimulation in response to the tyrosine kinase inhibitor PD153035. When A549 cells were first treated with $1 \mu \mathrm{M}$ PD153035 and 100 nM FND, followed by $224.02 \mathrm{~J} / \mathrm{cm}^{2} \mathrm{nNIR}$, the results (Figure 6A) showed that the MFC value sharply increased from $2.1 \pm 0.3$ to $3.4 \pm 0.3(p=0.003)$ within 10 min of nNIR irradiation, but the MFC value gradually decreases from $3.4 \pm 0.3$ to $2.8 \pm 0.3$ with the increase of time (black line). However, when A549 cells were treated with only $1 \mu \mathrm{M}$ PD153035 and $100 \mathrm{nM}$ FND, the MFC value decreased with time in the first $10 \mathrm{~min}$, where MFC varied from $1.8 \pm 0.3$ to $1.2 \pm 0.3(p=0.16)$, and the MFC tended to level off with the increase of time from $1.2 \pm 0.3$ to $1.3 \pm 0.3$ (brown line). Therefore, when A549 cells were treated with FND alone, the MFC $=2.1 \pm 0.1$ but when cells were treated with FND and PD153035 the MFC $=1.5 \pm 0.3$, which demonstrated that PD153035 promotes mitochondrial fusion. 


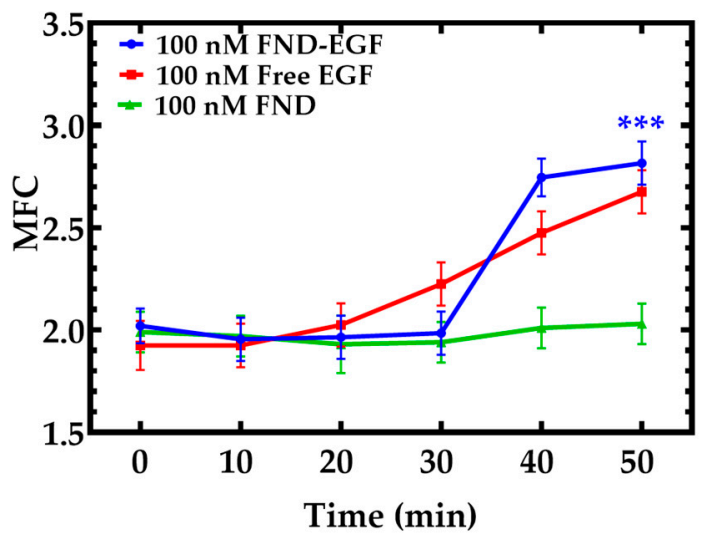

Figure 5. The MFC analysis of A549 cells treated with FNDs, free EGF, and FND-EGF. MFC for cells treated with free EGF showed a moderate increase in $\mathrm{MFC}(\mathrm{MFC}=2.7 \pm 0.1)$ but there was no change in MFC for cells treated with FND only $($ MFC $=2.1 \pm 0.1)$. The MFC of cells treated with $100 \mathrm{nM} \mathrm{FND}$ for $22 \mathrm{~h}$ then later treated with conjugated $100 \mathrm{nM}$ FND-EGF showed a very significant $(* * * p<0.01)$ increase in MFC $(2.8 \pm 0.2)$.

A

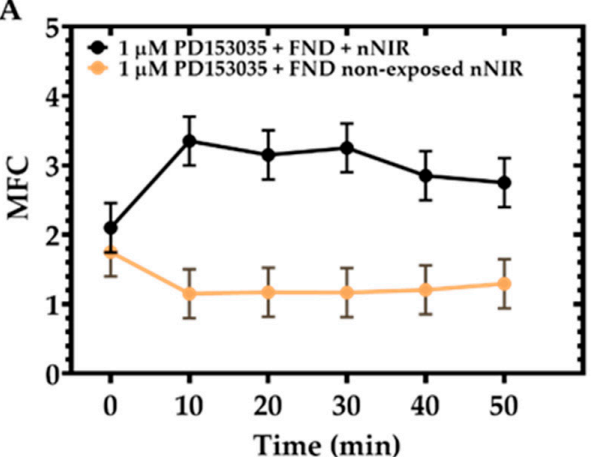

C

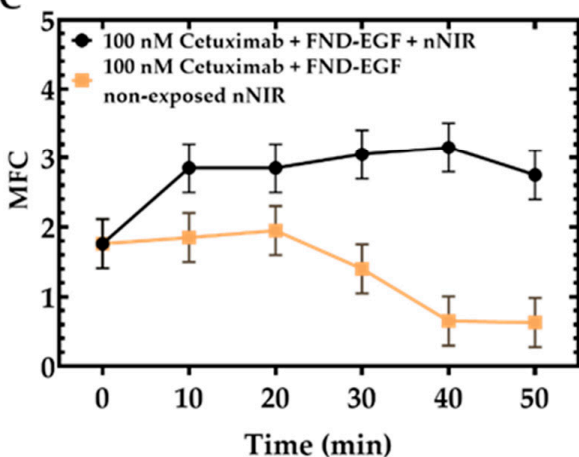

B

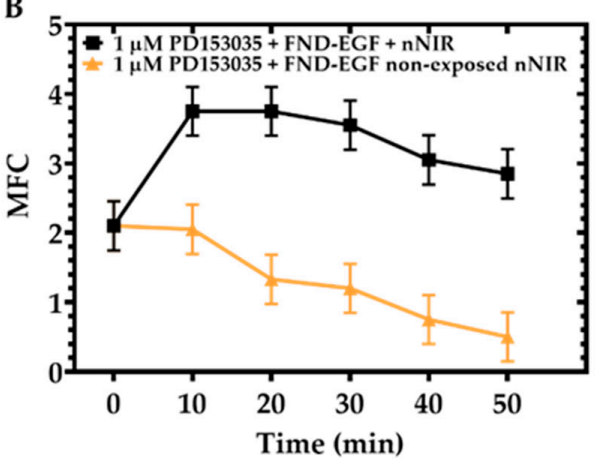

D

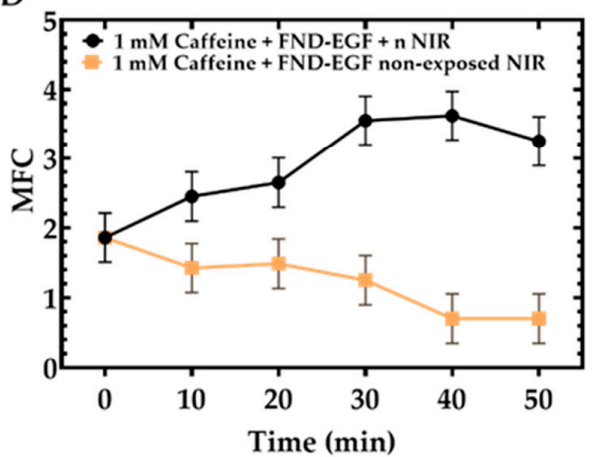

Figure 6. Drug treatment with A549 cells $(n=50)$ and exposed to $224.02 \mathrm{~J} / \mathrm{cm}^{2} \mathrm{nNIR}$. (A) illustrates cells treated with $1 \mu \mathrm{M}$ PD153035 and $100 \mathrm{nM}$ FND was exposed to $224.02 \mathrm{~J} / \mathrm{cm}^{2} \mathrm{nNIR}$ for $10 \mathrm{~s}$ there was an increase in MFC compared to non-nuclear exposed cell (MFC: $2.8 \pm 0.3 \mathrm{nNIR}$, vs. $1.3 \pm 0.3$ non-NIR). (B) illustrates cells treated with $1 \mu \mathrm{M}$ PD153035 and conjugated $100 \mathrm{nM}$ FND-EGF then exposed to $224.02 \mathrm{~J} / \mathrm{cm}^{2} \mathrm{nNIR}$ for $10 \mathrm{~s}$ and imaged at different time points, analysis showed an increase in MFC (MFC: $2.9 \pm 0.3 \mathrm{nNIR}$, vs. $0.5 \pm 0.3$ non-NIR) of cell nucleus exposed to NIR compared to non-nuclear exposed cells. Cetuximab treated A549 cells and conjugated $100 \mathrm{nM}$ FND-EGF were exposed to $224.02 \mathrm{~J} / \mathrm{cm}^{2} \mathrm{nNIR}$, and analysis showed an increase in MFC compared to the non-nuclear exposed cells (MFC: $2.8 \pm 0.3 \mathrm{nNIR}$ vs. $0.6 \pm 0.3$ non-NIR), as shown in (C). A549 cells treated with conjugated $100 \mathrm{nM}$ FND-EGF and $1 \mathrm{mM}$ caffeine were exposed to $224.02 \mathrm{~J} / \mathrm{cm}^{2} \mathrm{nNIR}$ at different time points. Analysis showed an increase in MFC of nuclear exposed cells compared to non-NIR cells (MFC: $3.3 \pm 0.3 \mathrm{nNIR}$, vs. $0.7 \pm 0.3$ non-NIR), as shown in (D). Statistical analysis was performed by one-way ANOVA. 
We then evaluated the effect of $\mathrm{nNIR}$ on A549 cells pretreated with cetuximab (100 nM) and FND-EGF (100 nM) and with caffeine (1 mM) and $100 \mathrm{nM}$ FND-EGF (100 nM). All A549 cells treated with drugs such as PD153035, cetuximab, and caffeine combined with FNDEGF all showed a decrease in MFCs, where a decrease in MFC for A549 cells treated with PD153035, cetuximab, and caffeine combined with FND-EGF from $2.1 \pm 0.3$ to $0.5 \pm 0.3$, $1.8 \pm 0.3$ to $0.6 \pm 0.3$ and $1.9 \pm 0.3$ to $0.7 \pm 0.3$, respectively, as can be seen in Figure $6 \mathrm{~B}-\mathrm{D}$. However, there was an increase in MFC for A549 cells treated FND-EGF from $2.1 \pm 0.1$ (time point $0 \mathrm{~min}$ ) to $2.8 \pm 0.2$ (time point $50 \mathrm{~min}$ ). Therefore, in the absence of nNIR irradiation, an increase in MFC due to the presence of FND-EGF will be inhibited by PD153035, cetuximab, and caffeine; these findings suggest these three drugs promote mitochondrial fusion.

\subsection{ComparativeAanalysis of A549 Cells Treated with Different Classes of Drugs and Then Exposed to $n N I R$}

Figure 7 summarizes the experimental results from Figure 3 to Figure 6. The MFC analysis demonstrated that the positive control mdivi-1 showed a significant decrease in MFC compared to the control; the negative control CCCP showed an increase in MFC compared to the control (Figure 7). In addition, all cells pretreated with the different classes of drugs ( $1 \mu \mathrm{M}$ PD153035, $1 \mathrm{mM}$ caffeine, and $100 \mathrm{nM}$ cetuximab) followed by $224.02 \mathrm{~J} / \mathrm{cm}^{2}$ $\mathrm{nNIR}$ irradiation showed significant decreases in the MFC compared to the cells exposed to nNIR irradiation only; however, the MFC values still more significant than the control, which implied nNIR irradiation of single A549 cells induces mitochondrial fission and an increase in MFC due to the presence of nNIR irradiation could suppress PD153035, caffeine, and cetuximab activities in this study.

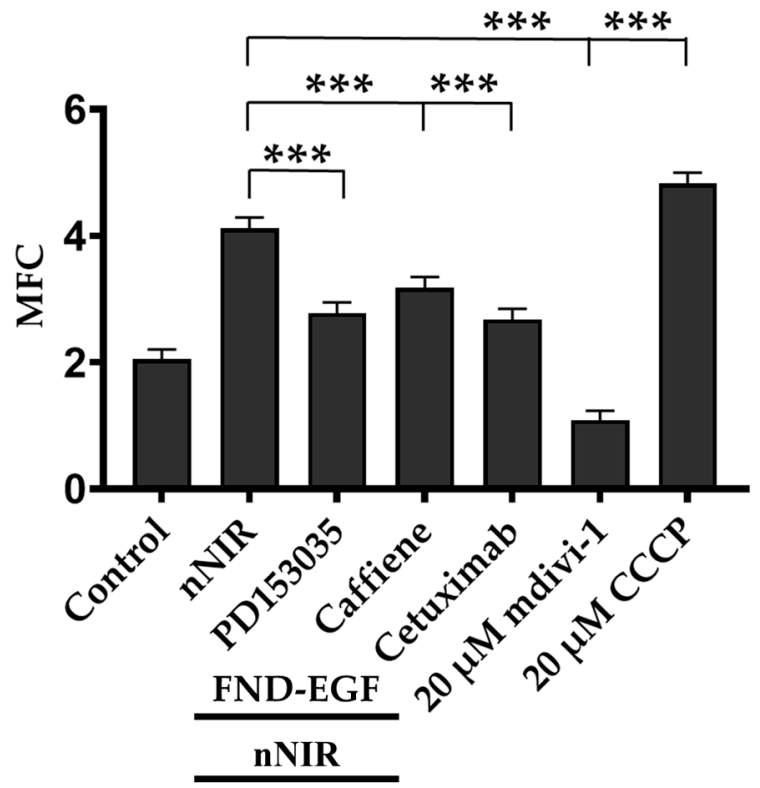

Figure 7. Comparative analysis of A549 cells exposed to $\mathrm{nNIR}$ and A549 cells treated with different classes of drugs ( $1 \mu \mathrm{M}$ PD153035 and $100 \mathrm{nM}$ FND/1 mM caffeine and $100 \mathrm{nM}$ FND/100 nM Cetuximab and $100 \mathrm{nM}$ FND) followed by exposure to nNIR. There was a significant ${ }^{* *} p<0.01$ increase MFC of nNIR compared to drug treated cells (MFC: $4.1 \pm 0.3$ nNIR cell vs. $2.9 \pm 0.3$ PD153035 treated cells, vs. $3.3 \pm 0.3$ caffeine treated cells vs. $2.8 \pm 0.3$ cetuximab treated cells). There was a significant ${ }^{* * *} p<0.01$ increase in MFC of nNIR compared to mdivi-1 (MFC: $4.1 \pm 0.3$ nNIR vs. $1.5 \pm 0.2$ mdivi- 1 treated cells). On the other hand, there was a significant ${ }^{* * *} p<0.01$ increase in MFC of CCCP treated cells compared to $\mathrm{nNIR}$ cell ( $4.3 \pm 0.2 \mathrm{CCCP}$ treated cells vs. $4.1 \pm 0.3 \mathrm{nNIR})$. 


\section{Discussion}

In this study, when a single cell nucleus was exposed to NIR, there was a sharp increase in MFC from 10 to $15 \mathrm{~min}$ then followed by a gradual increase in MFC after $15 \mathrm{~min}$ compared to non-exposed NIR cell (MFC: $3.7 \pm 0.2 \mathrm{nNIR}$ cell vs. $1.9 \pm 0.2$ non-exposed NIR cell) Figure 2B, we further investigated an average of 110 cells exposed to nucleus NIR compared to non-nucleus exposed cells, our data analysis showed that there was a sharp increase in MFC within 5 to 15 min in nucleus exposed cells compared to cytosol exposed cells that showed no change in MFC (MFC: $4.1 \pm 0.3$ nNIR; ${ }^{* * *} p<0.01$ vs. $2.1 \pm 0.3 \mathrm{cNIR}$ ) Figure 4D. We have shown in this study that single cell nucleus exposed to NIR leads to an increase in MFC and that 110 cells exposed to nucleus NIR and showed an increase in MFC. In this study, nNIR have shown to increase mitochondria fragmentation which leads to a higher MFC and studies have shown that mitochondrial contained nucleic acid [38], further studies have shown that DNA double-strand breaks (DSBs) is said to occur in the nucleus [39] by exposing cell nucleus to NNIR to cause the fragmentation of mitochondrial directly affect the nuclear DNA and therefore may lead to DNA damage. In summary, nNIR leads to the mitochondrial fragmentation and since mitochondrial contained nucleic acid [38] and that DNA controls the functional properties of nucleic acid by damaging the nucleic acid damages the DNA and since double strand break occurs in the nucleus and it is said to be a cytotoxic lesion nNIR may have enhance DNA damage and even double strand break (DSBs) [39]. Further studies are needed to use Phospho-Histone H2A.X (Ser139) (20E3) Rabbit mAb (Alexa Fluor ${ }^{\circledR} 647$ Conjugate) to demonstrate nucleus DNA damage. This dye can be used on cells that have been exposed to NIR light that may cause DNA damage by presenting a fragmented DNA in the nucleus.

Cells treated with free EGF showed a moderate increase in MFC (MFC $=2.7 \pm 0.1)$ on the other hand, cells treated with FND only showed no increase in MFC (MFC = 2.1 \pm 0.1$)$ and there was a small amount of non-specific uptake of FND in the cytosol of the cell (Supplementary Figure S1). These data have shown that due to the synergetic effects of increase concentration of FND and EGF tend to have influence an increase in MFC since studies have shown that a higher concentration of FND may lead to oxidative stress in the balance of energy metabolism and dysfunction of mitochondrial [40]. These two factors, that is the increased concentration of FND and the 100 nM EGF. may have influenced the increase in MFC (Figure 5). In order for us to determine the FND and EGF activity, A549 cells were treated with $100 \mathrm{nM}$ FND and incubated for $22 \mathrm{~h}$ we then treat these cells with conjugated $100 \mathrm{nM}$ FND-EGF another batch of cells were treated with $100 \mathrm{nM}$ free EGF and another set of cells were treated with FND only, our data analysis showed that cells treated with conjugated FND-EGF presented a high MFC $(2.8 \pm 0.2)$, and the fluorescence images shows very large amount of FND in the cytosolic domain of A549 cell (Supplementary Figure S2).

We further treated cells with PD153035 and FND and exposed the nucleus of these cells to $224.02 \mathrm{~J} / \mathrm{cm}^{2}$ NIR and treated another set of cells with PD153035 and FND only. Analysis showed a sharp increase in MFC of PD153035 exposed cells to NIR from 0 to $10 \mathrm{~min}$ (MFC from $2.1 \pm 0.3$ to $3.4 \pm 0.3$ ). However, there was a gradual decrease in the MFC from $3.4 \pm 0.3$ to $2.8 \pm 0.3$ (Figure 6A). Our data showed that cells treated with PD153035 and FND only showed a sharp decrease in MFC from 0 to $10 \mathrm{~min}$ MFC from $1.8 \pm 0.3$ to $1.2 \pm 0.3$ but was stable after $10 \mathrm{~min}$ (MFC $1.2 \pm 0.3$ to $1.3 \pm 0.3$ ), as shown in Figure $6 \mathrm{~A}$. On the other hand, this result shows that in the absence of nNIR, PD153035 will inhibit the signal pathway of EGF, and studies have shown that it is a potent inhibitor of EGF tyrosine kinase. However, it thus also binds to the DNA double-helical structures by insertion [19]; this may therefore lead to mitochondrial fusion, but on the other hand, in the presence of nNIR, PD153035 function may be suppressed, which may lead to DNA damage and that FND alone is not sufficient enough to suppress PD153035 activity (Figure 6A). However, when A549 cells were treated with $1 \mu \mathrm{M}$ PD153035 and 100 nM FND-EGF followed by $224.02 \mathrm{~J} / \mathrm{cm}^{2} \mathrm{nNIR}$, the results showed a sharp increase in MFC from $2.1 \pm 0.3$ to $3.7 \pm 0.3$ but gradually decreased from $3.7 \pm 0.3$ to $2.8 \pm 0.3$ with time in the first $10 \mathrm{~min}$, but the MFC tended to level off with the increase of time (Figure 6B). 
A total of $100 \mathrm{nM}$ of Cetuximab was treated with conjugated $100 \mathrm{nM}$ FND-EGF and the cell nucleus was exposed to NIR. Analysis showed a gentle increase in MFC from 10 to $20 \mathrm{~min}$ but was stable after $20 \mathrm{~min}$. On the other hand, cells were treated with conjugated 100 nM FND-EGF and100 nM Cetuximab, and data analysis showed that there was a stable MFC from 0 to $20 \mathrm{~min}$ but a sharp decrease in MFC from 20 to $40 \mathrm{~min}$ then it maintained stability MFC (MFC: $3.2 \pm 0.3$ nNIR, vs. $0.8 \pm 0.3$ non-exposed NIR), as shown in Figure $6 \mathrm{C}$. Note that when cells are exposed to nNIR in the presence of the cetuximab, the nNIR thus suppresses the cetuximab inhibitory effect. On the other hand, when cells are not exposed to $\mathrm{nNIR}$, cetuximab thus inhibits EGF even in the presence of FND. This observation demonstrated that in the presence of $\mathrm{nNIR}$, the inhibitor had been suppressed, resulting in an increase in MFC due to the nNIR DNA damage effect (Figure 6C).

Cells were also treated with $1 \mathrm{mM}$ caffeine, and the cell nucleus was exposed to NIR. Analysis showed an increase in MFC. On the other hand, cells treated with caffeine and conjugated FND-EGF only showed a decrease in MFC (MFC: $3.3 \pm 0.3$ nNIR cell, vs. $0.7 \pm 0.3$ non-exposed NIR cell), as shown in Figure 6D. These results showed that nNIR effect thus leads to an increase in MFC due to the DNA damage effect even in the presence of caffeine.

These MFC's were compared to a positive and negative control such as mdivi-1 and CCCP. Mdivi-1 inhibited mitochondrial fission [41] and CCCP mediated mitochondrial fission and mitophagy [42]. Using these two controls in our study, we were able to screen PD153035, cetuximab, and caffeine for their role in EGF inhibition in cancer treatment. Using these positive and negative control, we determined that all MFC values in our study above the control but below or equal to the CCCP MFC value were categorized as an increased MFC. This increase in MFC, therefore, leads to mitochondrial fission. On the other hand, all MFC values below the control but above the mdivi-1 MFC value were categorized as a decreased MFC. This decrease in MFC, therefore, leads to mitochondrial fusion. On the other hand, all MFCs in our study that were below the control but above the mdivi-1 MFCs values have been categorized as low MFC, a low MFC therefore leads to mitochondrial fusion. In our study using single cell nuclear NIR light and EGF in combination with treated drugs showed a significant increase in MFC compared to nonnuclear NIR exposed cells, and a significant decrease in MFC compared to only nNIR exposed cells (Figure 6). An increase in EGFR activities may lead to an increase in MFC. Cetuximab that can block EGFR activities $[43,44]$ was used in this study since it blocks EGFR activities, as supported in Figure 6C. But our result also showed that nNIR and FND-EGF may have suppresses cetuximab functions of EGFR inhibition. Caffeine was used in this study since it inhibits the enzyme phosphodiesterases and the calcium channel. This will, as a result, inhibit the DNA damage [45]. However, caffeine function may have been overridden in inhibiting DNA damage due to the presence of nNIR and FND-EGF. FND have been used in intracellular environments of different types of cells $[46,47]$ where they showed a very good biocompatibility [48]. Targeting nondiamond has previously been used in the diagnostics application in cancer and tumors [49]. It is also useful in the sense that they are very visible in different imaging techniques. However, an increase in FND concentration inside the cytosol domain may induce cell stress and the corresponding mitochondrial dynamics and therefore lead to mitochondrial dysfunction.

\section{Conclusions}

In this study, we demonstrated that when a single cell nucleus is exposed to NIR, this will increase MFC. Furthermore, this increase in MFC is associated with increased mitochondrial fission, resulting in mitochondrial fragmentation. Our study illustrated four unique findings. Firstly, single cell nNIR in the same image plane led to an increase in mitochondrial fragmentation compared to non-nuclear exposed single cell. Secondly, single cell nNIR showed a significant increase in MFC compared to cytosol single cell NIR. It is therefore worth noting that NIR have been used for the first time here to distinguish between two subcellular structure such as the nucleus and cytosol to demonstrate that $\mathrm{nNIR}$ leads an increase in MFC and to mitochondrial fission caused by the nNIR effect on 
DNA damage. Thirdly, we monitored the activities of EGF in A549 cell. This study has demonstrated that treating cells with conjugated FND-EGF have a significant increase effect on the MFC compared to either free EGF treated cells and cells treated with FND only and that we have shown that increased concentration of FND may induce cell stress, mitochondrial dysfunction caused by higher concentration of FND [30]. This have demonstrated the importance and limitations of a carrier such as a nanomaterial FND to enhance endocytosis of EGF into the cytosol domain of a cell to be able to determine EGF activities and to provide a better target for drug treatment but FND into the cytosol domain of a cell may induce cell stress, mitochondrial fragmentation, and mitochondrial dysfunction when FND in higher concentration. Fourthly, since EGF is of clinical importance in cancer therapeutics, we targeted EGF activities in the presence of different drugs and exposed cells to nNIR. Our data analysis has shown for the first time a significant increase in MFC's of cells exposed to nNIR. In this study, we targeted nNIR to demonstrate for the first time that nNIR leads to an increase in MFC and since mitochondrial contained nucleic acid [28] and the DNA controls the functional properties of nucleic acid and the DNA strand break is said to occur in the nucleus [29] we therefore concluded that the increase in MFC may have been caused by nNIR which leads to DNA damage and therefore resulted to mitochondrial fission. A comparative analysis of nNIR treated cells only showed that there was a significant increase in MFC compared to drug treated cells and to the controls cells but that all drugs treated cells exposed to nNIR showed a significant increase in MFC compared to the control and mdivi-1 the positive control this highlight that even in the presence of inhibitor such as cetuximab, PD153035 or caffeine nNIR suppresses these drug functions (Figure 7). In summary, the present study provided a fundamental important information about single cell exposure to nuclear NIR that will lead to the alteration of mitochondria dynamics which subsequently leads to an increase in MFC and therefore leads to mitochondrial fission but not cytosol exposed cells to NIR and that all cells treated with drugs but not exposed to nucleus NIR were all determined as been caused by mitochondrial fusion because of the drug EGF inhibitory effects. This study has demonstrated that all of these drugs when treated alone on cell did not prove to be effective against nNIR and all of these drugs are being liable to resistibility. We anticipate mitochondrial patterns can be used as biomarkers of cancer diagnosis and cancer drug response. In addition, the proposed single-cell method could be applied to construct a rapid screening method for the detection and therapeutic evaluation of many types of cancer.

Supplementary Materials: The following supporting information can be downloaded at: https: //www.mdpi.com/article/10.3390/cells11040624/s1, Figure S1: Comparison of the bright-field image of the A549 cell, the fluorescence image of the mitochondrial structure, and the simultaneous FND fluorescence image at 50 min time point, Figure S2: Comparison of the bright-field image of the A549 cell, the fluorescence image of the mitochondrial structure, and the simultaneous FND-EGF fluorescence image at $50 \mathrm{~min}$ time point.

Author Contributions: Conceptualization, T.-S.Y. and L.-S.L.; methodology, M.G. and T.-Y.S.; investigation, T.-J.W., Y.-J.C. and J.-F.C.; writing-review and editing, M.G., T.-S.Y. and L.-S.L. All authors have read and agreed to the published version of the manuscript.

Funding: This research was funded by the Ministry of Education, Taiwan, grant number DP2-11021121-01-O-06.

Institutional Review Board Statement: Not applicable.

Informed Consent Statement: Not applicable.

Data Availability Statement: Raw image data and analyzed data can be found in the attached folder and these data were generated during the study.

Acknowledgments: This work was financially supported by the TMU Research Center of Cancer Translational Medicine from the Featured Areas Research Center Program within the framework of the Higher Education Sprout Project by the Ministry of Education in Taiwan. (Grant numbers: DP2-11021121-03-C-06-01, DP2-110-21121-03-C-06-02, DP2-110-21121-03-C-06-03, DP2-109-21121-03-C-06-01, 
DP2-109-21121-03-C-06-02, DP2-109-21121-03-C-06-03.) This research was also partially supported by the Ministry of Science and Technology (Grant numbers: MOST-110-2320-B-038-056,MOST-110-2314B-038-138,MOST-109-2314-B-038-122,MOST-109-2314-B-038-141,MOST-109-2635-B-038-001,MOST-1092314-B-038-072, MOST 106-2320-B-038-03), Taipei Medical University (Grant number: TMU105-AE1B13) and National Health Research Institutes (Grant number: NHRI-EX109- 10713EI). The funders had no role in the design of the study, collection, analysis, and interpretation of the data, or the writing and publication of this manuscript. This work was financially supported by the TMU Research Center of Cancer Translational Medicine from the Featured Areas Research Center Program within the framework of the Higher Education Sprout Project by the Ministry of Education (MOE) in Taiwan. The authors thank the Ministry of Science and Technology of the Republic of China (MOST 107-2314-B-038-032-MY2) for their financial support for this research. We acknowledge funding from the Ministry of Science and Technology (Grant number: MOST 110-2221-E-155-043-MY3).

Conflicts of Interest: The authors declare no conflict of interest.

\section{References}

1. Chen, H.H.W.; Kuo, M.T. Improving radiotherapy in cancer treatment: Promises and challenges. Oncotarget 2017, 8, 62742-62758. [CrossRef] [PubMed]

2. Chen, G.; Cao, Y.; Tang, Y.; Yang, X.; Liu, Y.; Huang, D.; Zhang, Y.; Li, C.; Wang, Q. Advanced Near-Infrared Light for Monitoring and Modulating the Spatiotemporal Dynamics of Cell Functions in Living Systems. Adv. Sci. 2020, 7, 1903783. [CrossRef]

3. Shi, H.; Sadler, P.J. How promising is phototherapy for cancer? Br. J. Cancer 2020, 123, 871-873. [CrossRef]

4. Hua, X.-W.; Bao, Y.-W.; Wu, F.-G. Fluorescent carbon quantum dots with intrinsic nucleolus-targeting capability for nucleolus imaging and enhanced cytosolic and nuclear drug delivery. ACS Appl. Mater. Interfaces 2018, 10, 10664-10677. [CrossRef]

5. Pan, L.; Liu, J.; Shi, J. Cancer cell nucleus-targeting nanocomposites for advanced tumor therapeutics. Chem. Soc. Rev. 2018, 47, 6930-6946. [CrossRef]

6. Zhu, Y.X.; Jia, H.R.; Pan, G.Y.; Ulrich, N.W.; Chen, Z.; Wu, F.G. Development of a Light-Controlled Nanoplatform for Direct Nuclear Delivery of Molecular and Nanoscale Materials. J. Am. Chem. Soc. 2018, 140, 4062-4070. [CrossRef]

7. Gao, G.; Jiang, Y.W.; Yang, J.; Wu, F.G. Mitochondria-targetable carbon quantum dots for differentiating cancerous cells from normal cells. Nanoscale 2017, 9, 18368-18378. [CrossRef]

8. Jia, H.R.; Jiang, Y.W.; Zhu, Y.X.; Li, Y.H.; Wang, H.Y.; Han, X.; Yu, Z.W.; Gu, N.; Liu, P.; Chen, Z.; et al. Plasma membrane activatable polymeric nanotheranostics with self-enhanced light-triggered photosensitizer cellular influx for photodynamic cancer therapy. J. Control. Release 2017, 255, 231-241. [CrossRef]

9. Jia, H.R.; Zhu, Y.X.; Xu, K.F.; Liu, X.; Wu, F.G. Plasma membrane-anchorable photosensitizing nanomicelles for lipid raftresponsive and light-controllable intracellular drug delivery. J. Control. Release 2018, 286, 103-113. [CrossRef]

10. Li, S.Y.; Qiu, W.X.; Cheng, H.; Gao, F.; Cao, F.Y.; Zhang, X.Z. A Versatile Plasma Membrane Engineered Cell Vehicle for Contact-Cell-Enhanced Photodynamic Therapy. Adv. Funct. Mater. 2017, 27, 1604916. [CrossRef]

11. Yu, N.; Huang, L.; Zhou, Y.; Xue, T.; Chen, Z.; Han, G. Near-Infrared-Light Activatable Nanoparticles for Deep-Tissue-Penetrating Wireless Optogenetics. Adv. Healthc. Mater. 2019, 8, e1801132. [CrossRef]

12. Hong, G.; Antaris, A.L.; Dai, H. Near-infrared fluorophores for biomedical imaging. Nat. Biomed. Eng. 2017, 1, 0010. [CrossRef]

13. Nomura, S.; Morimoto, Y.; Tsujimoto, H.; Arake, M.; Harada, M.; Saitoh, D.; Hara, I.; Ozeki, E.; Satoh, A.; Takayama, E.; et al. Highly reliable, targeted photothermal cancer therapy combined with thermal dosimetry using a near-infrared absorbent. Sci. Rep. 2020, 10, 9765. [CrossRef] [PubMed]

14. Kholimatussa'diah, S.; Astuti, S.D.; Apsari, R. Determination of Infrared Laser Energy Dose for Cancer Cells Inactivation as a Candidate of Photodynamic Therapy. In Journal of Physics: Conference Series; IOP Publishing: Bristol, UK, 2020 ; p. 012021.

15. Kim, C.K.; Adhikari, A.; Deisseroth, K. Integration of optogenetics with complementary methodologies in systems neuroscience Nat. Rev. Neurosci. 2017, 18, 222-235. [CrossRef] [PubMed]

16. Che, T.F.; Lin, C.W.; Wu, Y.Y.; Chen, Y.J.; Han, C.L.; Chang, Y.L.; Wu, C.T.; Hsiao, T.H.; Hong, T.M.; Yang, P.C. Mitochondrial translocation of EGFR regulates mitochondria dynamics and promotes metastasis in NSCLC. Oncotarget 2015, 6, 37349. [CrossRef]

17. Wu, S.; Xing, D. Intracellular signaling cascades following light irradiation. Laser Photonics Rev. 2014, 8, 115-130. [CrossRef]

18. Parra, V.; Eisner, V.; Chiong, M.; Criollo, A.; Moraga, F.; Garcia, A.; Härtel, S.; Jaimovich, E.; Zorzano, A.; Hidalgo, C.; et al. Changes in mitochondrial dynamics during ceramide-induced cardiomyocyte early apoptosis. Cardiovasc. Res. 2008, 77, 387-397. [CrossRef]

19. Yao, C.H.; Wang, R.; Wang, Y.; Kung, C.P.; Weber, J.D.; Patti, G.J. Mitochondrial fusion supports increased oxidative phosphorylation during cell proliferation. Elife 2019, 8, e41351. [CrossRef]

20. Iqbal, S.; Hood, D.A. Oxidative stress-induced mitochondrial fragmentation and movement in skeletal muscle myoblasts. Am. J. Physiol. Cell Physiol. 2014, 306, C1176-C1183. [CrossRef]

21. Frank, S.; Oliver, L.; Lebreton-De Coster, C.; Moreau, C.; Lecabellec, M.T.; Michel, L.; Vallette, F.M.; Dubertret, L.; Coulomb, B. Infrared radiation affects the mitochondrial pathway of apoptosis in human fibroblasts. J. Investig. Dermatol. 2004, 123, 823-831. [CrossRef] 
22. Thomas, R.; Weihua, Z. Rethink of EGFR in Cancer With Its Kinase Independent Function on Board. Front. Oncol. 2019, 9, 800. [CrossRef] [PubMed]

23. Shaw, A.T.; Kim, T.M.; Crino, L.; Gridelli, C.; Kiura, K.; Liu, G.; Novello, S.; Bearz, A.; Gautschi, O.; Mok, T.; et al. Ceritinib versus chemotherapy in patients with ALK-rearranged non-small-cell lung cancer previously given chemotherapy and crizotinib (ASCEND-5): A randomised, controlled, open-label, phase 3 trial. Lancet Oncol. 2017, 18, 874-886. [CrossRef]

24. Kim, D.W.; Tiseo, M.; Ahn, M.J.; Reckamp, K.L.; Hansen, K.H.; Kim, S.W.; Huber, R.M.; West, H.L.; Groen, H.J.M.; Hochmair, M.J.; et al. Brigatinib in Patients With Crizotinib-Refractory Anaplastic Lymphoma Kinase-Positive Non-Small-Cell Lung Cancer: A Randomized, Multicenter Phase II Trial. J. Clin. Oncol. 2017, 35, 2490-2498. [CrossRef]

25. Jung, M.J.; Woo, C.G.; Lee, S.; Chin, S.; Kim, H.K.; Kwak, J.J.; Koh, E.S.; Lee, B.; Jang, K.T.; Moon, A. Gene copy number variation and protein overexpression of EGFR and HER2 in distal extrahepatic cholangiocarcinoma. Pathology 2017, 49, 582-588. [CrossRef]

26. Yang, Y.P.; Ma, H.; Starchenko, A.; Huh, W.J.; Li, W.; Hickman, F.E.; Zhang, Q.; Franklin, J.L.; Mortlock, D.P.; Fuhrmann, S.; et al. A Chimeric Egfr Protein Reporter Mouse Reveals Egfr Localization and Trafficking In Vivo. Cell Rep. 2017, 19, 1257-1267. [CrossRef]

27. Freed, D.M.; Bessman, N.J.; Kiyatkin, A.; Salazar-Cavazos, E.; Byrne, P.O.; Moore, J.O.; Valley, C.C.; Ferguson, K.M.; Leahy, D.J.; Lidke, D.S.; et al. EGFR Ligands Differentially Stabilize Receptor Dimers to Specify Signaling Kinetics. Cell 2017, 171, 683-695.e618. [CrossRef]

28. Kang, N.; Cao, S.; Jiang, B.; Zhang, Q.; Donkor, P.O.; Zhu, Y.; Qiu, F.; Gao, X. Cetuximab enhances oridonin-induced apoptosis through mitochondrial pathway and endoplasmic reticulum stress in laryngeal squamous cell carcinoma cells. Toxicol. Vitr. 2020, 67, 104885. [CrossRef]

29. Mok, T.; Cheng, Y.; Zhou, X.; Lee, K.H.; Nakagawa, K.; Niho, S.; Tsuji, F.; Rosell, R.; Corral Jaime, J.; Migliorino, M.R. Dacomitinib versus gefitinib for the first-line treatment of advanced EGFR mutation positive non-small cell lung cancer (ARCHER 1050): A randomized, open-label phase III trial. J. Clin. Oncol. 2017, 35, LBA9007. [CrossRef]

30. Whitlow, J.; Pacelli, S.; Paul, A. Multifunctional nanodiamonds in regenerative medicine: Recent advances and future directions. J. Control. Release 2017, 261, 62-86. [CrossRef]

31. Suarez-Kelly, L.P.; Campbell, A.R.; Rampersaud, I.V.; Bumb, A.; Wang, M.S.; Butchar, J.P.; Tridandapani, S.; Yu, L.; Rampersaud, A.A.; Carson III, W.E. Fluorescent nanodiamonds engage innate immune effector cells: A potential vehicle for targeted anti-tumor immunotherapy. Nanomed. Nanotechnol. Biol. Med. 2017, 13, 909-920. [CrossRef]

32. Gerstenhaber, J.A.; Marcinkiewicz, C.; Barone, F.C.; Sternberg, M.; D'Andrea, M.R.; Lelkes, P.I.; Feuerstein, G.Z. Biocompatibility studies of fluorescent diamond particles-(NV) 800 nm (part V): In vitro kinetics and in vivo localization in rat liver following long-term exposure. Int. J. Nanomed. 2019, 14, 6451. [CrossRef] [PubMed]

33. Barone, F.C.; Marcinkiewicz, C.; Li, J.; Feng, Y.; Sternberg, M.; Lelkes, P.I.; Rosenbaum-Halevi, D.; Gerstenhaber, J.A.; Feuerstein, G.Z. Long-term biocompatibility of fluorescent diamonds-(NV)-Z 800 nm in rats: Survival, morbidity, histopathology, particle distribution and excretion studies (part IV). Int. J. Nanomed. 2019, 14, 1163. [CrossRef] [PubMed]

34. Lin, Y.W.; Liao, W.S.; Lin, J.; Liu, K.K.; Cheng, H.C.; Wang, C.C.; Li, Y.; Chen, C.; Chao, J.I. Delivery of paclitaxel and cetuximab by nanodiamond enhances mitotic catastrophe and tumor inhibition in colorectal cancer. FASEB J. 2016, 30, 1107.6.

35. Li, D.; Chen, X.; Wang, H.; Liu, J.; Zheng, M.; Fu, Y.; Yu, Y.; Zhi, J. Cetuximab-conjugated nanodiamonds drug delivery system for enhanced targeting therapy and 3D Raman imaging. J. Biophotonics 2017, 10, 1636-1646. [CrossRef] [PubMed]

36. Durand, M.J.; Ait-Aissa, K.; Levchenko, V.; Staruschenko, A.; Gutterman, D.D.; Beyer, A.M. Visualization and quantification of mitochondrial structure in the endothelium of intact arteries. Cardiovasc. Res. 2019, 115, 1546-1556. [CrossRef] [PubMed]

37. Rehman, J.; Zhang, H.J.; Toth, P.T.; Zhang, Y.; Marsboom, G.; Hong, Z.; Salgia, R.; Husain, A.N.; Wietholt, C.; Archer, S.L. Inhibition of mitochondrial fission prevents cell cycle progression in lung cancer. FASEB J. 2012, 26, 2175-2186. [CrossRef]

38. Saki, M.; Prakash, A. DNA damage related crosstalk between the nucleus and mitochondria. Free Radic. Biol. Med. 2017, 107, $216-227$. [CrossRef]

39. Dwivedi, G.; Haber, J.E. Assaying Mutations Associated With Gene Conversion Repair of a Double-Strand Break. Methods Enzymol. 2018, 601, 145-160.

40. Fresta, C.G.; Chakraborty, A.; Wijesinghe, M.B.; Amorini, A.M.; Lazzarino, G.; Lazzarino, G.; Tavazzi, B.; Lunte, S.M.; Caraci, F.; Dhar, P. Non-toxic engineered carbon nanodiamond concentrations induce oxidative/nitrosative stress, imbalance of energy metabolism, and mitochondrial dysfunction in microglial and alveolar basal epithelial cells. Cell Death Dis. 2018, 9, 245. [CrossRef]

41. Bordt, E.A.; Clerc, P.; Roelofs, B.A.; Saladino, A.J.; Tretter, L.; Adam-Vizi, V.; Cherok, E.; Khalil, A.; Yadava, N.; Ge, S.X.; et al. The Putative Drp1 Inhibitor mdivi-1 Is a Reversible Mitochondrial Complex I Inhibitor that Modulates Reactive Oxygen Species. Dev. Cell 2017, 40, 583-594. [CrossRef]

42. Li, G.-B.; Zhang, H.-W.; Fu, R.-Q.; Hu, X.-Y.; Liu, L.; Li, Y.-N.; Liu, Y.-X.; Liu, X.; Hu, J.-J.; Deng, Q. Mitochondrial fission and mitophagy depend on cofilin-mediated actin depolymerization activity at the mitochondrial fission site. Oncogene 2018, 37, 1485-1502. [CrossRef] [PubMed]

43. Sabra, R.; Billa, N.; Roberts, C.J. Cetuximab-conjugated chitosan-pectinate (modified) composite nanoparticles for targeting colon cancer. Int. J. Pharm. 2019, 572, 118775. [CrossRef] [PubMed]

44. Gurdal, H.; Tuglu, M.M.; Bostanabad, S.Y.; Dalkilic, B. Partial agonistic effect of cetuximab on epidermal growth factor receptor and Src kinase activation in triplenegative breast cancer cell lines. Int. J. Oncol. 2019, 54, 1345-1356. [CrossRef] [PubMed]

45. Cui, W.Q.; Wang, S.T.; Pan, D.; Chang, B.; Sang, L.X. Caffeine and its main targets of colorectal cancer. World J. Gastrointest. Oncol. 2020, 12, 149-172. [CrossRef] 
46. Hemelaar, S.R.; van der Laan, K.J.; Hinterding, S.R.; Koot, M.V.; Ellermann, E.; Perona-Martinez, F.P.; Roig, D.; Hommelet, S.; Novarina, D.; Takahashi, H.; et al. Generally Applicable Transformation Protocols for Fluorescent Nanodiamond Internalization into Cells. Sci. Rep. 2017, 7, 5862. [CrossRef]

47. Chipaux, M.; van der Laan, K.J.; Hemelaar, S.R.; Hasani, M.; Zheng, T.T.; Schirhagl, R. Nanodiamonds and Their Applications in Cells. Small 2018, 14, 1704263. [CrossRef]

48. Hemelaar, S.R.; Saspaanithy, B.; L'Hommelet, S.R.M.; Perona Martinez, F.P.; van der Laan, K.J.; Schirhagl, R. The Response of HeLa Cells to Fluorescent NanoDiamond Uptake. Sensors 2018, 18, 355. [CrossRef]

49. Hemelaar, S.R.; de Boer, P.; Chipaux, M.; Zuidema, W.; Hamoh, T.; Martinez, F.P.; Nagl, A.; Hoogenboom, J.P.; Giepmans, B.N.G.; Schirhagl, R. Nanodiamonds as multi-purpose labels for microscopy. Sci. Rep. 2017, 7, 720. [CrossRef] 